\title{
Preparation of Micron-Sized Di-Functional Magnetic Composite Polymer Particles
}

\author{
Hasan Ahmad ${ }^{1}$, Tania Tofaz ${ }^{1}$, Mohammad Wali Ullah Oli ${ }^{1}$, Mohammad Abdur Rahman, \\ Mohammad Abdul Jalil Miah ${ }^{1}$, Klaus Tauer ${ }^{2}$ \\ ${ }^{1}$ Department of Chemistry, Rajshahi University, Rajshahi, Bangladesh; ${ }^{2}$ MPI of Colloid and Interfaces, Am Mühlenberg, Golm, Germany. \\ Email: samarhass@yahoo.com, Klaus.tauer@mpikg.mpg.de
}

Received May $22^{\text {nd }}, 2010$; revised June $17^{\text {th }}, 2010$; accepted July $7^{\text {th }}, 2010$.

\begin{abstract}
In this investigation micron-sized monodisperse magnetic composite polymer particles with amino and amide functional groups were prepared considering their applications in biotechnology. First, polystyrene/poly (acrylic acid-acrylamide-N-N-methylene-bis-acrylamide) [PS/P(AA-AAm-MBAAm)] composite polymer particles were prepared by seeded copolymerization. The carboxyl groups present on or near the particles surface were modified by amine-nucleophile, ethylene diamine (EDA), through pre-activation with dicyclohexyl carbodiimide as coupling agent. The aminated particles were then magnetically modified and named as aminated-Fe ${ }_{3} \mathrm{O}_{4}$ composite particles. Formation of such magnetic composite particles was confirmed by scanning electron micrographs, FTIR-spectra and magnetic susceptibility measurement. The produced composite particles were paramagnetic. To see the relative hydrophilic character of the particles surface the adsorption behavior of trypsin (TR) as biomolecule was studied on PS particles and aminated-Fe $\mathrm{O}_{3} \mathrm{O}_{4}$ composite particles. The magnitude of adsorbed TR on PS particles was higher than that on aminated-Fe ${ }_{3} \mathrm{O}_{4}$ composite particles.
\end{abstract}

Keywords: Aminated $\mathrm{Fe}_{3} \mathrm{O}_{4}$ Composite, Amino and Amide Groups, Trypsin, Hydrophilic

\section{Introduction}

In recent years polymer particles with well defined particle size and various reactive functional groups on the surface are attracting much interest because of their applications in a broad range of fields, e.g. as binders in paints, adhesives, paper coating, textile and as a solid support in the biochemical and biological field as well as in catalysis and calibration standards [1-5]. The functional groups include hydroxyl [6-8], aldehyde [9-11], carboxyl [1216], amino [17-19], epoxy [20-22], cyano [23], sulfhydryl [24] and chloromethyl groups [25-27]. A variety of methods are available to produce monodispersed particles in the micrometer-size range. Of these, dispersion polymerization in non-aqueous media allows successful preparation of micron-sized polymer particles with ease [28-33]. However, this methodology has suffered drawbacks when functional monomers were employed [34, 35]. These limitations include polydispersity, odd-shaped particles and in extreme case coagulation during polymerization. Moreover, the presence of functional comonomers in dispersion copolymerization produces polymer particles with limited number of functional groups on the surface. To overcome these limitations dispersion pol- ymerization followed by seeded copolymerization is expected to be suitable to prepare functional polymer particles in the micrometer-size range.

The carboxyl group is one of the most widely studied functional groups for polymer particles intended for biomedical or diagnostic applications. This functional group can undergo easy derivatization using water/oil- soluble coupling agents. In a previous work $\mathrm{H}$. Ahmad et al. reported the amination of carboxyl functionalized submicron-sized copolymer latex particles using amine-nucleophiles [36]. The present work is an extension of this early work, emphasizing the precipitation of magnetic nanoparticles on the surface of micron-sized aminated composite polymer particles to diversify their applications in magnetic support based separation in various fields of biotechnology and biomedicine, like cell separation [37], enzyme immobilization [38,39], drug delivery [40], and protein separation $[41,42]$. Most of the works available in the literature are concerned with preparation of nano to submicron-sized magnetic latex particles [43-50] and a few with micron-sized latex particles [51,52] bearing identical functional group. To prepare magnetic latex particles numerous routes have been investigated. They include the precipitation of iron oxide submicron particles 
in presence of water soluble polymers [53-55], polymerization of suitable monomer mixtures in presence of iron oxide particles stabilized by surfactants [56-58] and layer-by-layer self-assembly of alternating layers of polyelectrolytes and magnetic nanoparticles onto colloidal templates [59]. In a recent work, preparation of submicron-sized sulfate- and carboxyl-functionalized magnetite/ polystyrene spheres is reported for further deposition of gold nanoparticles [60]. Despite the success of these approaches little attention has been made for the preparation of di-functional micron-sized magnetic latex particles.

The present work aims to describe the preparation of monodispersed micron-sized magnetic composite particles bearing amino and amide groups on or near the particles surface. The produced di-functional magnetic latexes, named as aminated- $\mathrm{Fe}_{3} \mathrm{O}_{4}$ latexes, would offer advantagees in biomedical applications as amino functional group can be utilized for coupling of affinity ligands or binding of biomolecules and the remaining amide functional group can simultaneously be used to modify the particles surface or even can act as spacer among the immobilized biomolecules preventing self reaction.

\section{Experimental Details}

\subsection{Materials}

Styrene (S) and acrylic acid (AA) purchased from Fluka, Chemika, Switzerland, were distilled under reduced pressure to remove inhibitors and preserved in the refrigerator until use. Acrylamide (AAm) from LOBA Chem. India and N,N'-methylene-bis-acrylamide (MBAAm) from Sigma, Chemical Company, USA, a crosslinking agent were used without any purification. 2,2'-Azobisisobutyronitrile (AIBN) and potassium persulfate (KPS) both from LOBA Chem. India, were recrystallized from ethanol and distilled water respectively and preserved in the refrigerator before use. Poly(N-vinylpyrrolidone) (PVP) from Fluka, Chemika, Switzerland of molecular weight $3.6 \times 10^{5} \mathrm{~g} / \mathrm{mol}$ was used as a polymeric stabilizer. Tricaprylylmethylammonium chloride (aliquate ${ }^{336}$ ) from Fluka, Chemika, Switzerland was used as a cationic costabilizer. The biomolecule used was trypsin (TR) from E. Merck, Germany, used as adsorbent on the surface of polymer particles without any purification. Dicyclohexyl carbodiimide (DCC), ethylene diamine (EDA) all from LOBA Chem. India, were used as supplied. Ferric chloride hexahydrate $\left(\mathrm{FeCl}_{3} \cdot 6 \mathrm{H}_{2} \mathrm{O}\right)$, ferrous sulphate $\left(\mathrm{FeSO}_{4}\right)$, sodium hydroxide $(\mathrm{NaOH})$, oleic acid and other chemicals were of analytical grade. Deionized water was distilled using a glass (Pyrex) distillation apparatus.

Scanning Electron Microscope, SEM (LEO Electron Microscopy Ltd., UK); Burker Proton NMR, $250 \mathrm{MHz}$; FTIR (8044 Simadzu, Japan); Centrifuge machine from Kokuson Corporation, Tokyo, Japan; Helios gamma single-beam UV-Visible spectrophotometer from Unicam,
UK; HI 9321 Microprocessor pH-meter and conductivity meter both from HANNA instruments, Portugal were used in this study. NICOMP 380 (USA) particles sizer was used to measure hydrodynamic diameter of the polymer particles. Sherwood Scientific Magnetic Susceptibility Balance was used for susceptibility measurement. Thermal analysis was carried out using thermogravimetry (TG) analyser from Seiko Instruments Inc EXSTAR 6000 TG/ DTA 6300.

\subsection{Preparation of Polystyrene (PS) Seed Particles}

Polystyrene (PS) seed particles were prepared by dispersion polymerization of $10 \mathrm{~g}$ styrene in presence of PVP $(0.432 \mathrm{~g})$ and aliquate $\mathrm{e}^{336}(0.123 \mathrm{~g})$ using $0.162 \mathrm{~g}$ AIBN as oil soluble initiator. The dispersion media used was ethanol $(65 \mathrm{~mL})$ and the polymerization was carried out in a $250 \mathrm{~mL}$ three necked round bottom flask under a nitrogen atmosphere at $70^{\circ} \mathrm{C}$ for $24 \mathrm{~h}$. The conversion was nearly $100 \%$ as measured gravimetrically.

\subsection{Preparation of Micron-Sized Composite Polymer Particles}

Micron-sized PS/P(AA-AAm-MBAAm) composite polymer particles were prepared by seeded copolymerization of AA, AAm and MBAAm in presence PS seed particles. Prior to the seeded copolymerization PS seed particles were transferred into water and magnetically stirred with AA, AAm and MBAAm comonomers at room temperature for $12 \mathrm{~h}$ in order to minimize the formation of soluble copolymer. The reaction flask was then transferred to a preheated thermostat water bath maintained at $70^{\circ} \mathrm{C}$. The polymerization reaction was carried out under a nitrogen atmosphere for $12 \mathrm{~h}$ using KPS as an initiator. Polymerization conditions are shown in Table 1.

\subsection{Measurement of Hydrodynamic Particle Size}

PS/P(AA-AAm-MBAAm) composite polymer particles were washed by serum replacement to remove any unreacted monomer and initiator fragments. A dilute dispersion of approximately $0.01 \%$ polymer solid was prepared,

Table 1. Preparation of PS/P(AA-AAm-MBAAm) ${ }^{\text {a) }}$ composite polymer particles ${ }^{\text {b) }}$

\begin{tabular}{ccc}
\hline \multicolumn{2}{l}{ Ingredients } & \\
\hline PS dispersion & \\
AA & $(\mathrm{g})$ & 29.5130 \\
AAm & $(\mathrm{g})$ & 0.8881 \\
MBAAm & $(\mathrm{g})$ & 0.8759 \\
KPS & $(\mathrm{g})$ & 0.036 \\
Water & $(\mathrm{g})$ & 0.29 \\
& $(\mathrm{~g})$ & 60.0 \\
\hline
\end{tabular}

${ }^{\text {a) }}$ Core/shell ratio: $1 / 0.6 ;{ }^{\text {b) }} 70^{\circ} \mathrm{C}, \mathrm{N}_{2}, 120 \mathrm{rpm}, 24 \mathrm{~h}$; ${ }^{\mathrm{c}}$ Polymer solid, 4.89 $\mathrm{g} / \mathrm{L}$ 
$\mathrm{pH}$ was adjusted using acid/alkali solution and intensity weighted average hydrodynamic size was measured by NICOMP particle size. Each sample was measured twice and the average value is reported. The deviation between successive measurements was less than $\pm 5 \%$.

\subsection{Amination of PS/P (AA-AA-MBAAm) Composite Particles}

PS/P(AA-AA-MBAAm) latex particles were transferred from water to ethanol medium by ultra-centrifugal washing at $12,000 \mathrm{rpm}$ and the solid content of the latex was adjusted to about 2\%. EDA was covalently bonded to the carboxyl groups of composite particles by the following method [36].

Pre-activation method: $50 \mathrm{~g}$ of latex dispersion was mixed with $2.1166 \mathrm{~g}$ coupling agent (DCC) in a reagent bottle, magnetically stirred at $25^{\circ} \mathrm{C}$ for $1 \mathrm{~h}$. The activated carboxyl group was then reacted with $0.6154 \mathrm{~g}$ EDA at $25^{\circ} \mathrm{C}$ for $3 \mathrm{~h}$ and then again at $0^{\circ} \mathrm{C}$ for $24 \mathrm{~h}$.

\subsection{Preparation of Aminated-Fe $\mathrm{O}_{3}$ Composite Particles}

$2.5 \mathrm{~g}$ of modified aminated composite particles were taken in a round bottom flask containing $70 \mathrm{~mL}$ water. The dispersion was cooled $\left(0-5^{\circ} \mathrm{C}\right)$ in an ice-water bath under a nitrogen gas bubbling. $0.5 \mathrm{~g}(3 \mathrm{mmol})$ of $\mathrm{FeCl}_{3} \cdot 6 \mathrm{H}_{2} \mathrm{O}$ and $0.2558 \mathrm{~g}(2.7 \mathrm{mmol})$ of $\mathrm{FeSO}_{4}$ were dissolved in $25 \mathrm{~mL}$ water. Then the iron solution was added to the flask containing the aminated composite dispersion. A light brown color mixture was formed. The ice bath was removed and the flask was immersed in a preheated water bath at $85^{\circ} \mathrm{C}$. Immediately, $2.9123 \mathrm{~mL}$ of $5 \mathrm{M}$ aqueous $\mathrm{NaOH}$ solution was added. The reaction mixture gradua- lly turned to black. The mixture was kept stirring at $85^{\circ} \mathrm{C}$ for $2 \mathrm{~h}$. Oleic acid $(0.01456 \mathrm{~g}, 2.26 \mathrm{mmol})$ was slowly added towards the end of the process to stabilize the aminated- $\mathrm{Fe}_{3} \mathrm{O}_{4}$ dispersion. Then the dispersion was cooled to room temperature. The resultant magnetic particles were centrifuged and thoroughly washed with deionized distilled water, followed by $0.1 \mathrm{M} \mathrm{HCl}$ and again by deionized distilled water.

\subsection{Measurement of Magnetic Susceptibility}

Aminated- $\mathrm{Fe}_{3} \mathrm{O}_{4}$ composite particles were washed, separated from their dispersion by centrifugation and dried in oven at $80^{\circ} \mathrm{C}$ for $2 \mathrm{~h}$. The dried powders were placed in a pre-weighed sample tube and measured the magnetic susceptibility $\left(\chi_{\mathrm{g}}\right)$ using the following equation:

$$
\chi_{g}=\frac{C \times L \times\left(R-R_{0}\right)}{m \times 10^{9}}
$$

where, $C$ is calibration constant of the balance, $L$ is length of the sample, $R_{0}$ and $R$ are reading of the empty and sample tubes and $M$ is weight of the sample (dry basis) in C.G.S unit.

\subsection{Thermogravimetric Analysis (TGA) of Aminated-Fe $\mathrm{O}_{3}$ Composite Polymer Particles}

Thermal properties of the dried aminated- $\mathrm{Fe}_{3} \mathrm{O}_{4}$ powder was measured by heating samples under flowing nitrogen atmosphere from $40^{\circ} \mathrm{C}$ to $600^{\circ} \mathrm{C}$ at a heating rate of $20^{\circ} \mathrm{C}$ $/ \mathrm{min}$ and the weight loss was recorded.

\subsection{Adsorption of Trypsin (TR) on PS Seed and Aminated-Fe $\mathrm{O}_{3}$ Composite Polymer Particles}

A mixture of $20 \mathrm{~mL}$ was prepared from purified polymer dispersion (polymer solid $0.15 \mathrm{~g}$ ) and TR $(200 \mathrm{mg} / \mathrm{g}$ ). The $\mathrm{pH}$ value of the mixture was immediately adjusted at the isoelectric point ( $\mathrm{pH}$ 10.0) using a buffer solution. In each measurement the dispersion-TR mixture was allowed to stand at $25^{\circ} \mathrm{C}$ for $45 \mathrm{~min}$. Polymer particles were then separated by centrifugation at $10,000 \mathrm{rpm}$ for $10 \mathrm{~min}$. In order to remove wafting particles completely, the supernatant was centrifuged once more. The concentration of TR in the supernatant was determined by a UV-visible spectrophotometer at the wavelength of 280 nm. The magnitude of TR adsorbed was calculated by subtracting the concentration of TR in the medium from that of the initial concentration. Calibration curve was used for this purpose.

\section{Results and Discussion}

Figures 1(a) and (b) shows the SEM photographs of PS and PS/P(AA-AAm-MBAAm) composite polymer particles. The average diameters and coefficient of variations are $1.47 \mu \mathrm{m}$ and $5.87 \%$ for PS seed and $1.51 \mu \mathrm{m}$ and $2.43 \%$ for PS/P(AA-AAm-MBAAm) composite particles. The average size of PS/P(AA-AAm-MBAAm) composite particles increased slightly after seeded copolymerization. Both the PS seed particles and the composite polymer particles are fairly monodispersed and spherical, having a smooth homogeneous surface. Submicron-sized P(AA-AAmMBAAm) copolymer particles are not observed. This suggests that seeded copolymerization of AA, AAm and MBAAm proceeds smoothly on PS seed particles, with
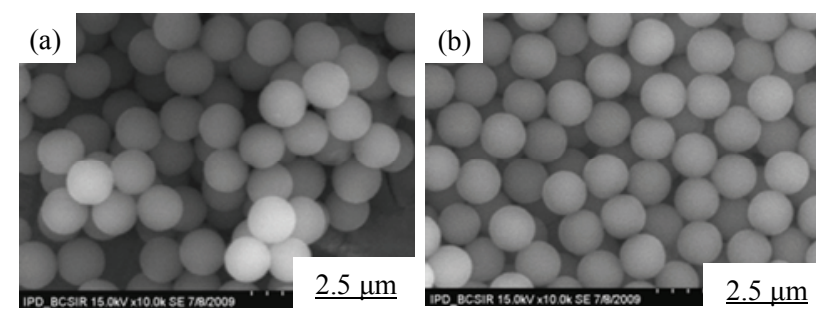

Figure 1. SEM photographs of (a) PS seed; (b) PS/P(AAAAm-MBAAm) composite polymer particles 
out any secondary nucleation.

Figure 2 shows the FTIR spectra of PS seed particles and PS/P(AA-AAm-MBAAm) composite polymer particles. Both polymer particles were washed and dried at $70^{\circ} \mathrm{C}$ prior to the recording of FTIR spectra. In the spectrum of PS/P(AA-AAm-MBAAm) composite particles a broad O-H stretching of carboxyl group appeared at $2400-3500 \mathrm{~cm}^{-1}$. The signal due to N-H stretching of primary amide expected to appear at $3200-3500 \mathrm{~cm}^{-1}$ is possibly been overlapped with $\mathrm{O}-\mathrm{H}$ stretching signal. The inclusion of moisture may also affect the appearance of N-H stretching. Distinct but weak signals due to $\mathrm{C}=\mathrm{O}$ stretching vibration for $-\mathrm{COOH}$ and $-\mathrm{CONH}_{2}$ groups in composite particles are appeared at around 1718 and $1690 \mathrm{~cm}^{-1}$, respectively. The combination band due to phenyl ring of PS largely affected the appearance of those stretching signals. The weak stretching signals of $-\mathrm{COOH}$ and $-\mathrm{CONH}_{2}$ groups are attributed to the smaller total surface area of micron-sized composite particles.

Figure 3 shows the ${ }^{1} \mathrm{H}$ NMR spectrum of PS/P(AAAAm-MBAAm) composite polymer particles. The chemical shifts of the aliphatic groups $-\mathrm{CH}_{2}$ and $-\mathrm{CH}$ appeared at $1.4 \mathrm{ppm}$ and $1.86 \mathrm{ppm}$, respectively. The intense signal due to aromatic protons from PS ring is observed at $6.6 \mathrm{ppm}$. The characteristic NMR signals due to acidic $(-\mathrm{COOH})$ and amidic $\left(-\mathrm{CONH}_{2}\right)$ protons are expected to be at 10.0-12.0 ppm and 5.0-9.0 ppm, respectively. But it is known that the chemical shifts of these groups are variable, depend not only on the chemical environment, but also on concentration, temperature, and solvent [61]. In the magnified spectra of composite particles, signals appeared at $8.1 \mathrm{ppm}$ and $4.68 \mathrm{ppm}$, indicated the presence of $-\mathrm{COOH}$ and $-\mathrm{CONH}_{2}$ groups. The deviation of both signals to upfield is due to possible hydrogen bonding between amide and carboxyl groups, hence

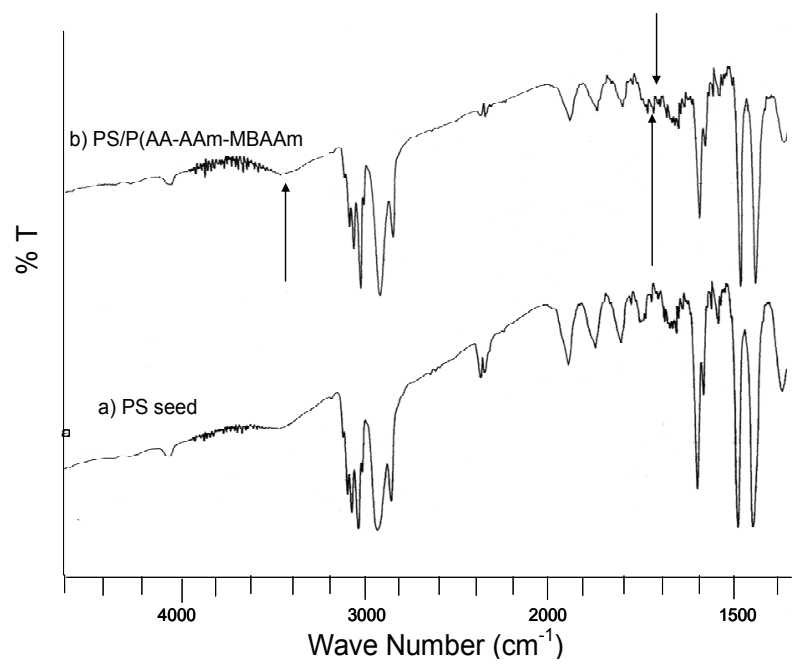

Figure 2. FTIR spectra of a) PS and b) PS/P(AA-AAmMBAAm) composite polymer particles the protons are shielded. The weak signal intensity of $-\mathrm{COOH}$ and $-\mathrm{CONH}_{2}$ groups are attributed to the poor solubility of cross-linked hydrophilic composite particles in non-polar $\mathrm{CDCl}_{3}$. Additionally, the presence of - $\mathrm{COOH}$ and $-\mathrm{CONH}_{2}$ was also confirmed by elemental and functional group analyses.

Figure 4 shows the variation of hydrodynamic diameter of washed PS/P(AA-AAm-MBAAm) composite polymer particles with different $\mathrm{pH}$ values at $20^{\circ} \mathrm{C}$. Hydrodynamic diameter increased with the increase of $\mathrm{pH}$ value. This behavior indicates that at lower $\mathrm{pH}$ value the composite polymer particles are relatively hydrophobic as the majority of carboxyl groups derived from AA comonomer is protonated. Whereas with increasing $\mathrm{pH}$ value more and more carboxyl groups are deprotonated, which facilitated the swelling of composite polymer particles through hydrogen bonding with water.

Figure 5 shows the SEM photographs of aminated PS/P(AA-AAm-MBAAm) composite, magnetite $\left(\mathrm{Fe}_{3} \mathrm{O}_{4}\right)$,

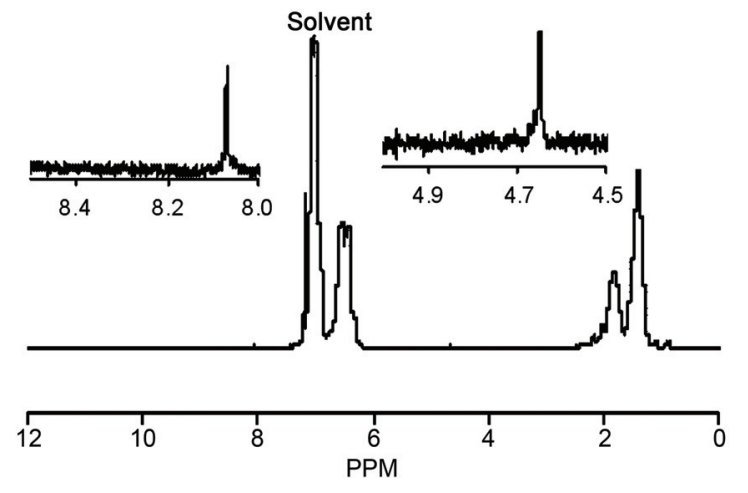

Figure 3. 1H NMR spectrum of composite polymer particles

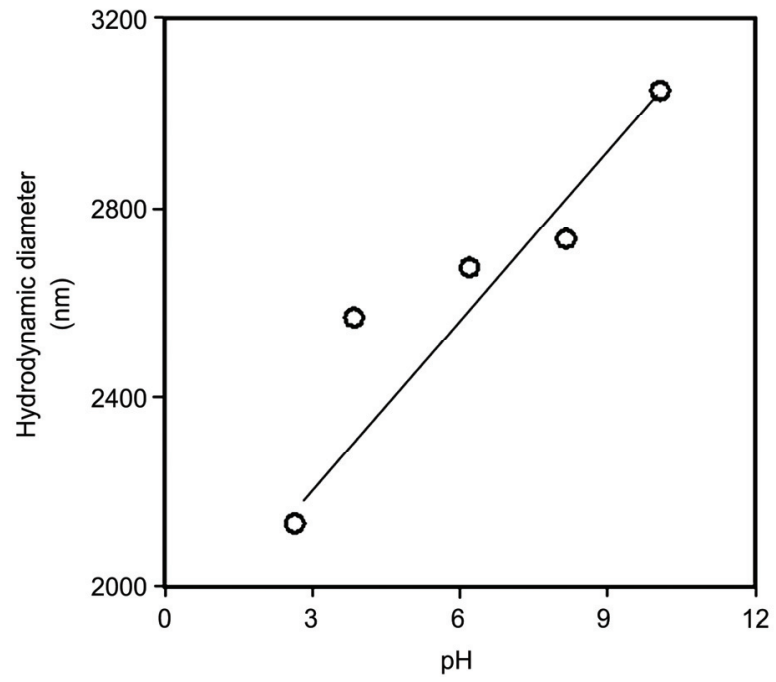

Figure 4. Variation of average hydrodynamic diameter of washed PS/P(AA-AAm-MBAAm) composite polymer particles with $\mathrm{pH}$ values measured at $20^{\circ} \mathrm{C}$ 
and aminated- $\mathrm{Fe}_{3} \mathrm{O}_{4}$ composite particles. All the particles were washed by serum replacement prior to the observation by SEM. It is to be mentioned that after three washings the supernatant obtained from the aminated- $\mathrm{Fe}_{3} \mathrm{O}_{4}$ composite particles was clear indicating no leaching of $\mathrm{Fe}_{3} \mathrm{O}_{4}$ particle. The observed magnetite $\left(\mathrm{Fe}_{3} \mathrm{O}_{4}\right)$ particles were prepared by co-precipitation of $\mathrm{Fe}^{2+}(\mathrm{aq})$ and $\mathrm{Fe}^{3+}$ (aq) in presence of $\mathrm{NaOH}$ and aminated- $\mathrm{Fe}_{3} \mathrm{O}_{4}$ composite particles were prepared by the impregnation of iron ions and precipitation of $\mathrm{Fe}_{3} \mathrm{O}_{4}$ on aminated composite polymer particles. The mean diameter of aminated- $\mathrm{Fe}_{3} \mathrm{O}_{4}$ composite particles is $1.60 \mu \mathrm{m}$ which is greater than the mean diameter of aminated composite polymer particles $(1.54 \mu \mathrm{m})$. It is also observed that after amination the average size of composite particles slightly increased as compared to that before amination $(1.51 \mu \mathrm{m})$. Similar increase in average size after amination was also observed in our previous work [36]. The surface of the aminated composite polymer particles is smooth but the surface of the aminated- $\mathrm{Fe}_{3} \mathrm{O}_{4}$ composite particles is not smooth with many small $\mathrm{Fe}_{3} \mathrm{O}_{4}$ particles attached to the surface of aminated composite particles. Additionally, the precipitation of $\mathrm{Fe}_{3} \mathrm{O}_{4}$ particles on aminated composite surface was confirmed by the measurement of magnetic susceptibility and the value was recorded as positive $(2.4768 \times$ $\left.10^{-4}\right)$. This result suggests that the prepared aminated$\mathrm{Fe}_{3} \mathrm{O}_{4}$ composite particles are paramagnetic. Prior to this measurement the dispersion was centrifuged and dried at low temperature $\left(80^{\circ} \mathrm{C}\right)$ to prevent any crystal deformation of the impregnated $\mathrm{Fe}_{3} \mathrm{O}_{4}$ particles.

Figure 6 shows the FTIR spectra of magnetite $\left(\mathrm{Fe}_{3} \mathrm{O}_{4}\right)$ and aminated- $\mathrm{Fe}_{3} \mathrm{O}_{4}$ composite particles. In the FTIR spectra of $\mathrm{Fe}_{3} \mathrm{O}_{4}$, the characteristic stretching vibrations due to $\mathrm{Fe}-\mathrm{O}$ bonds of $\mathrm{Fe}_{3} \mathrm{O}_{4}$ particles appeared at 582.5 and $439.7 \mathrm{~cm}^{-1}$ respectively, as also reported elsewhere [62,
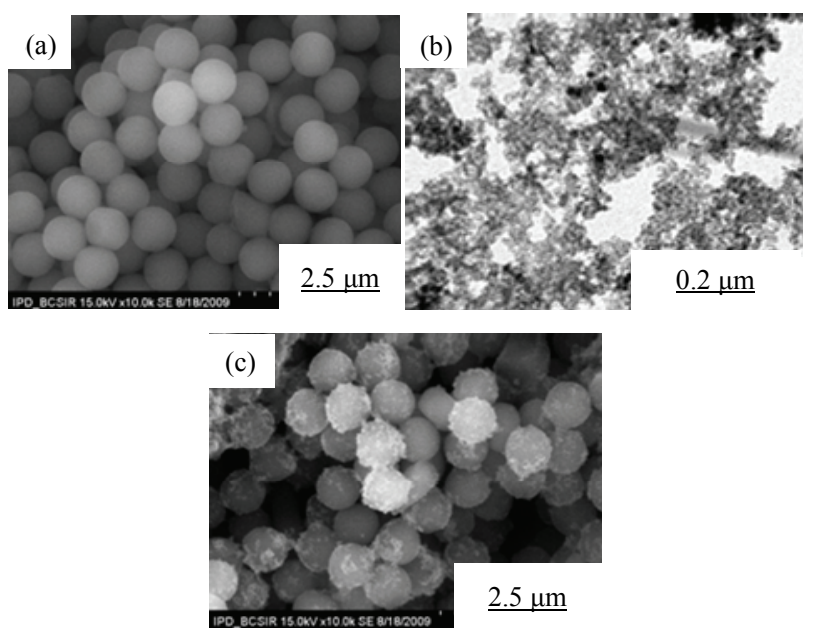

Figure 5. SEM photographs of (a) aminated PS/P(AA-AAmMBAAm) composite polymer; (b) magnetite $\left(\mathrm{Fe}_{3} \mathrm{O}_{4}\right)$; (c) aminated-Fe $\mathrm{F}_{3} \mathrm{O}_{4}$ composite particles
63]. The broad band at $3330.8 \mathrm{~cm}^{-1}$ can be assigned to the stretching vibration of surface water molecules or the envelope of hydrogen bonded surface $\mathrm{OH}$ groups. In aminated- $\mathrm{Fe}_{3} \mathrm{O}_{4}$ composite particles a combined strong signal for $\mathrm{N}-\mathrm{H}$ and $-\mathrm{OH}$ stretching derived from amide, carboxyl and surface water molecules is appeared at 3404.1 $\mathrm{cm}^{-1}$. The stretching signal due to $\mathrm{Fe}-\mathrm{O}$ is also observed in aminated- $\mathrm{Fe}_{3} \mathrm{O}_{4}$ composite particles at around $439 \mathrm{~cm}^{-1}$ and the signal appeared at $540 \mathrm{~cm}^{-1}$ broadened due to the out of plane $\mathrm{C}-\mathrm{H}$ bending vibration for substituted phenyl ring of PS. The above results also confirmed that the $\mathrm{Fe}_{3} \mathrm{O}_{4}$ particles have successfully been precipitated on the aminated composite polymer particles. TGA was used to determine the total inorganic material i.e. iron oxide content in aminated- $\mathrm{Fe}_{3} \mathrm{O}_{4}$ composite particles. TGA curve is illustrated in Figure 7. It is expected that as theaminated- $\mathrm{Fe}_{3} \mathrm{O}_{4}$ composite particles are heated from ambient temperature to $600^{\circ} \mathrm{C}$, the organic part of the

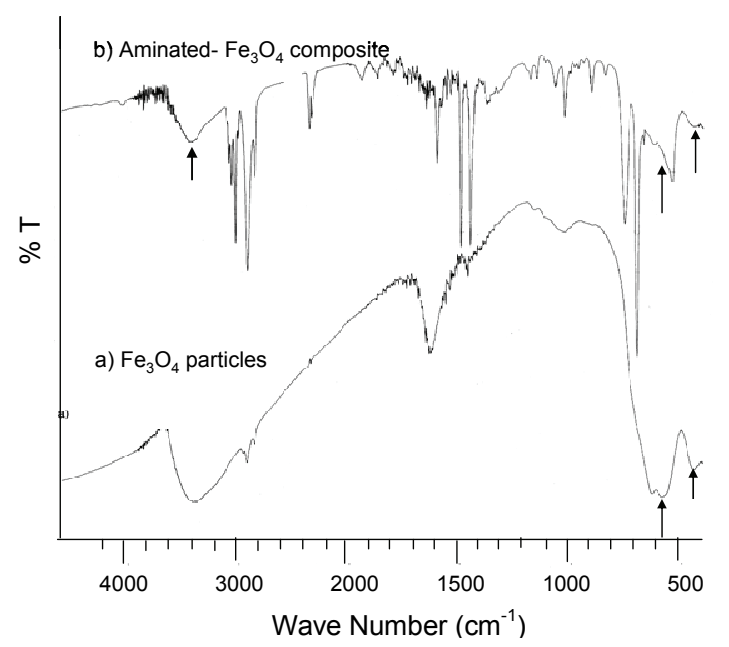

Figure 6. FTIR spectra of a) magnetite $\left(\mathrm{Fe}_{3} \mathrm{O}_{4}\right)$; b) aminated- $\mathrm{Fe}_{3} \mathrm{O}_{4}$ composite polymer particles

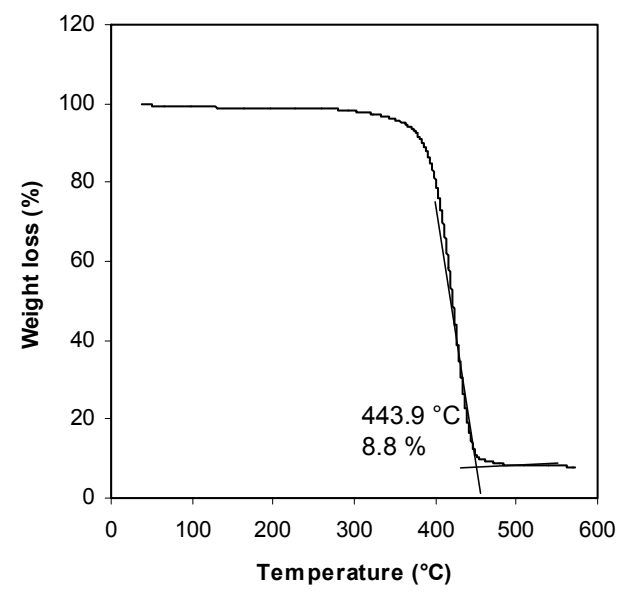

Figure 7. TGA thermogram of aminated- $\mathrm{Fe}_{3} \mathrm{O}_{4}$ composite polymer particles 
composite would be burned and the percentage of the remaining part after calcination would give the iron oxide content. As such TGA thermogram indicates that about $8.8 \%(\mathrm{w} / \mathrm{w})$ magnetic $\mathrm{Fe}_{3} \mathrm{O}_{4}$ nano-particles are precipitated on the aminated composite polymer particles. Considering the larger average size of the composite particles, the percentage of magnetic iron oxide is pretty high to modify the particles surface [64].

Figure 8 shows the adsorption behaviors of TR on the PS seed and aminated- $\mathrm{Fe}_{3} \mathrm{O}_{4}$ composite particles. It is well known that magnitude of adsorption is largely dependent on the degree of hydrophobic interaction between the particle surface and biomolecules and also on the total particle surface area. Since the sizes of the seed and aminated- $\mathrm{Fe}_{3} \mathrm{O}_{4}$ composite particles are not the same as measured from the SEM photographs, so the adsorption behavior of TR has been presented per unit area of the particles. The magnitude of adsorption on the aminated$\mathrm{Fe}_{3} \mathrm{O}_{4}$ composite particles is lower than that on PS seed particles. As already mentioned, in order to use polymer particles, as a carrier for biomolecules, the particle surface should be sufficiently hydrophilic with limited amount of hydrophobicity. It is well known that the strong hydrophobic interaction of biomolecules with solid surface results in the loss of native conformation as well as the activity of adsorbed biomolecule.

\section{Conclusions}

A synthetic rout for the preparation of monodisperse micron-sized magnetic composite polymer particles with amine and amide functional groups on or near the surface has been developed. The process involved the preparation of micron-sized PS latex particle by dispersion polymerization followed by seeded copolymerization with AA, AAm and MBAAm, surface modification with EDA and subsequent precipitation of iron ions to form $\mathrm{Fe}_{3} \mathrm{O}_{4}$.

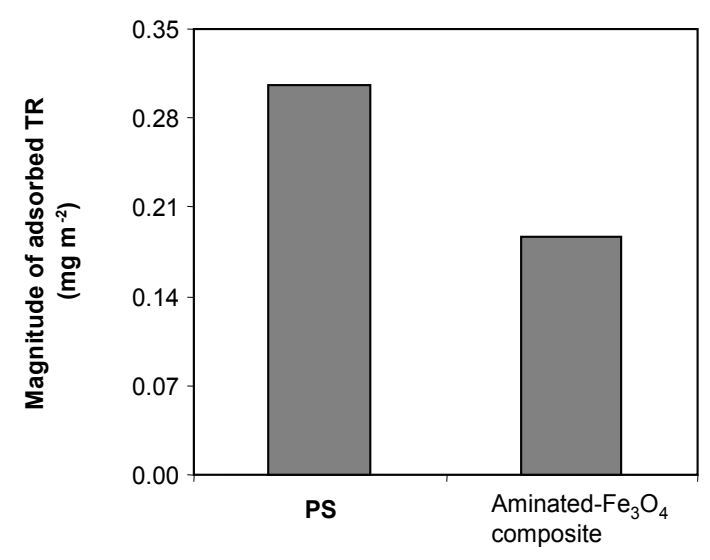

Figure 8. Magnitude of trypsin (TR) adsorbed on PS seed and aminated- $\mathrm{Fe}_{3} \mathrm{O}_{4}$ composite particles measured under the constant concentration against the total solid content at $25^{\circ} \mathrm{C}$. pH: 10.0; particles: $0.15 \mathrm{~g}$; TR: $200 \mathrm{mg} / \mathrm{g}$ of particles
The presence of amino and amide groups improved hydrophilicity and hence could prevent nonspecific adsorption of proteins.

\section{Acknowledgements}

This work was supported by the financial grant from MOSICT, Dhaka (Economic code: 3-2605-3993-5921).

\section{REFERENCES}

[1] C. Picot, "Position Paper: Functional Polymer Latexes," Polymer for Advanced Technologies, Vol. 6, No. 7, 1995, pp. 427-434.

[2] Q. Wang, S. Fu and T. Yu, "Emulsion Polymerization," Progress in Polymer Science, Vol. 19, No. 4, 1994, pp. 703-753.

[3] J-W. Kim, J-G. Park, J-H. Ryu, I-S. Chang and K-D. Suh, "Monodisperse Chloromethyl-Functionalized Macroporous Polymer Particles by Seeded Polymerization in Aqueous Media," Colloid and Polymer Science, Vol. 283, No. 11, 2005, pp. 1233-1240.

[4] M-O. Jung, J-H. Ryu, J-G Park, J-B. Jun and K-D. Suh, "Surface Modification of Monodisperse-Crosslinked Polymeric Microspheres Using a Redox Initiation System," Journal of Applied Polymer Science, Vol. 100, No. 2, 2006, pp. 1349-1356.

[5] H. Ahmad, M. M. Rahman and M. A. J. Miah, "Preparation of Micron-sized Epoxy Functionalized Polystyrene Particles and Adsorption of Biomolecules," Journal of Polymer Materials, Vol. 21, No. 1, 2005, pp. 27-36.

[6] B. Charleux, C. Pichot and M. F. Llauro, "Styreneterminated Poly(vinyl alcohol) Macromonomers: 2. Freeradical (Co)polymerization Studies and Application to the Functionalization of Latex Particles," Polymer, Vol. 34, No. 2, 1993, pp. 4352-4359.

[7] H. Ahmad, M. A. J. Miah, M. S. Pervin and M. M. Rahman, "Composite Polymer Particles Prepared with Different Amounts of Acrylic Acid and Their Usefulness as Carriers for Biomolecules," Colloid and Polymer Science, Vol. 281, No. 10, 2003, pp. 988-992.

[8] A. M. I. Ali, P. Pareek, L. Sewell, A. Schmid, S. Fujii, S. P. Armes and I. M. Shirley, "Synthesis of Poly (2-hydroxypropyl methacrylate) Latex Particles Via Aqueous Dispersion Polymerization," Soft Matter, Vol. 3, No. 5, 2007, pp. 1003-1013.

[9] S. Margel and E. Wiesel, "Acrolein Polymerization: Monodisperse, Homo and Hybrido Microspheres, Synthesis, Mechanism, and Reactions," Journal of Polymer Science, Polymer Chemistry Edition, Vol. 22, No. 1, 1984, pp. 145158.

[10] M. Okubo, Y. Kondo and M. Takahashi, "Production of Submicron-Size Monodisperse Polymer Particles Having Aldehyde Groups by Seeded Aldol Condensation," Colloid and Polymer Science, Vol. 271, No. 2, 1993, pp. 109113.

[11] P. Lei, J. Xu, Q. Wang and C. Wu, "Surface Functionalization of Polymer Latex Particles: 4. Tailor-Making of 
Aldehyde-functional Poly(methylstyrene) Latexes in an Emulsifier-Free System, Langmuir, Vol. 16, No. 9, 2000, pp. 4141-4147.

[12] K. Kang, C. Kan, Y. Du and D. Liu, "Synthesis and Properties of Soap-Free Poly(Methyl Methacrylate-Ethyl Acrylate-Methacrylic Acid) Latex Particles Prepared by Seeded Emulsion Polymerization," European Polymer Journal, Vol. 41, No. 3, 2005, pp. 439-445.

[13] X. Z. Kong and E. Ruckenstein, "Monodisperse Core/ shell Latex Particles Containing Carboxylic Acid Groups and their Optimum Acid Content for Pore Generation," Journal of Applied Polymer Science, Vol. 71, No. 9, 1999, pp. 1455-1460.

[14] J.-S. Song, L. Chagai and M. A. Winnik, "Monodisperse Micrometer-Size Carboxyl-functionalized Polystyrene Particles Obtained by Two-Stage Dispersion Polymerization," Macromolecules, Vol. 19, No. 17, 2006, pp. 57295737.

[15] H. Ahmad, M. M. Hossain, M. M. Rahman and M. A. J. Miah, "Monodispersed Carboxylated Composite Polymer Microspheres and Physical Immobilization of Biomolecules," Polymer Journal, Vol. 39, No. 5, 2007, pp. 428-434.

[16] T. Ding, E. S. Daniels, M. S. El-Aasser and A. Klein, "Synthesis and Characterization of Functionalized Polymer Latex Particles through a Designed Semicontinuous Emulsion Polymerization Process," Journal of Applied Polymer Science, Vol. 97, No. 1, 2005, pp. 248-256.

[17] T. Delair, V. Marguet, C. Pichot and B. Mandrand, "Synthesis and Characterization of Cationic Amino Functionalized Polystyrene Latexes," Colloid and Polymer Science, Vol. 272, No. 8, 1994, pp. 962-970.

[18] I. Miraballes-Martínez, A. Martín-Molina, F. GalisteoGonzález and J. Forcada, "Synthesis of Amino-Functionalized Latex Particles by a Multistep Method," Journal of Polymer Science Polymer Chemistry Edition, Vol. 39, No. 17, 2001, pp. 2929-2936.

[19] Z. Ma, Y. Guan and H. Liu, "Synthesis and Characterization of Micron-Sized Monodisperse Superparamagnetic Polymer Particles with Amino Groups," Journal of Polymer Science Polymer Chemistry, Vol. 43, No. 15, 2005, pp. 3433-3439.

[20] D. Horace and P. Caporal, "Reactive Poly(Lucidly Methacrylate) Microspheres Prepared by Dispersion Polymerization," Journal of Polymer Science Polymer Chemistry, Vol. 38, No. 21, 2000, pp. 3855-3863.

[21] J. M. Jin, J. M. Lee, M. H. Ha, K. Lee and S. Choe, "Highly Crosslinked Poly(Glycidyl Methacrylate-co-Divinyl Benzene) Particles by Precipitation Polymerization," Polymer, Vol. 48, No. 11, 2007, pp. 3107-3115.

[22] B. Gong, J. Zhu, L. Li, K. Qiang and L. Ren, "Synthesis of Non-Porous Poly(Glycidyl Methacrylate-co-EthyleneDimethacrylate) Beads and their Application in Separation of Biopolymers," Talanta, Vol. 68, No. 3, 2006, pp. 666-672.

[23] X. Lu, D. Huang, X. Yang and W. Huang, "Preparation of Narrow or Monodisperse Polymer Microspheres with
Cyano Group by Distillation-Precipitation Polymerization," Polymer Bulletin, Vol. 56, No. 2-3, 2006, pp. 171178.

[24] T. Delair, C. Pichot and B. Mandrand, "Synthesis and Characterization of Cationic Latex Particles Bearing Sulfhydryl Groups and their Use in the Immobilization of Fab Antibody Fragments (1)," Colloid and Polymer Science, Vol. 272, No. 1, 1994, pp. 72-81.

[25] T. Bahar and A. Tuncel, "Monodisperse Poly (p-chloromethylstyrene) Microbeads by Dispersion Polymerization," Polymer Engineering and Science, Vol. 39, No. 10, 1999, pp. 1849-1855.

[26] H. Ahmad, N. Saito, Y. Kagawa and M. Okubo, "Preparation of Micrometer-Sized Monodisperse 'Janus' Composite Polymer Particles Having Temperature-Sensitive Polymer Brushes at Half of the Surface by Seeded Atom Transfer Radical Polymerization," Langmuir, Vol. 24, No. 3, 2008, pp. 688-691.

[27] S. Baruch-Sharon and S. Margel, "Preparation and Characterization of Core-Shell Polystyrene/Polychloromethylstyrene and Hollow Polychloromethylstyrene Micrometer-sized Particles of Narrow-size Distribution," Colloid and Polymer Science, Vol. 287, No. 7, 2009, pp. 859-869.

[28] K. E. J. Barrett, "Dispersion Polymerization in Organic Meidia," British Polymer Journal, Vol. 5, No. 4, 1973, pp. 259-271.

[29] C. M. Tseng, Y. Y. Lu, M. S. El-Aasser and J. W. Vanderhoff, "Uniform Polymer Particles by Dispersion Polymerization in Alcohol," Journal of Polymer Science Polymer Chemistry Edition, Vol. 24, No. 11, 1986, pp. 2995-3007.

[30] T. Okaya, K. Kikuchi, A. Sukuki and N. Ikeda, "Dispersion Polymerization of Vinyl Acetate in a Mixture of Ethanol and Water," Polymer International, Vol. 54, No. 1, 2005, pp. 143-148.

[31] D. Hérault, C. Saluzzo and M Lemaire, "Preparation of Monodisperse Enantiomerically Pure Glycidyl Methacrylate-Ethylene Glycol Dimethacrylate Copolymers in Dispersion Copolymerization: Functionalization," Reactive and Functional Polymers, Vol. 66, No. 5, 2006, pp. 567-577.

[32] S. Jiang, E. D. Sudol, V. L. Dimonie and M. S. El-Aasser, "Kinetics of Dispersion Polymerization of Methyl Methacrylate and $n$-Butyl Acrylate: Effect of Initiator Concentration, Macromolecules, Vol. 40, No. 14, 2007, pp. 4910-4916.

[33] H. Ahmad, B. M. Chaki, M. M. Rahman, M. A. J. Miah and K. Tauer, "Solvency Effect of the Dispersion Medium on the Radical Polymerization of Styrene in NonAqueous Dispersion Media," E-Polymers, No. 080, 2007. http://www.e-polymers.org

[34] J. S. Song, F. Tronc and M. A. Winnik, "Two-Stage Dispersion Polymerization toward Monodisperse, Controlled Micrometer-Sized Copolymer Particles," Journal of American Chemical Society, Vol. 126, No. 21, 2004, pp. 65626563.

[35] M. Yasuda, H. Seki, H. Yokoyama, H. Ogino, K. Ishimi 
and H. Ishikawa, "Simulation of a Particle Formation Stage in the Dispersion Polymerization of Styrene" Macromolecules, Vol. 34, No. 10, 2001, pp. 3261-3270.

[36] H. Ahmad, M. E. Hossain, M. A. Rahman, M. M. Rahman, M. A. J. Miah and K. Tauer, "Carboxyl Functionalized Poly(Methyl Methacrylate-Acrylic Acid-Ethylene Glycol Dimethacrylate) Copolymer Particles and Their Amination with Amine-Nucleophiles," E-Polymers, No. 096. 2008. http//www.e-polymers.org

[37] P. Kronick and R. W. Gilpin, "Use of Superparamagnetic Particles for Isolation of Cells," Journal of Biochemical and Biophysical Methods, Vol. 12, No. 1-2, 1986, pp. 73-80.

[38] X. Li and Z. H. Sun, "Synthesis of Magnetic Polymer Microspheres and Application for Immobilization of Proteinase of Balillus Sublitis," Journal of Applied Polymer Science," Vol. 58, No. 11, 1995, pp. 1991-1997.

[39] X. Liu, Y. Guan, R. Shen and H. Liu, "Immobilization of Lipase onto Micron-Size Magnetic Beads," Journal of Chromatography B, Vol. 822, No. 1-2, 2005, pp. 91-97.

[40] T. K. Jain, M. A. Morales, S. K. Sahoo, D. L. SesliePelecky and V. Labhasetwar, "Iron Oxide Nanoparticles for Sustained Delivery of Anticancer Agents," Molecular Pharmaceutics, Vol. 2, No. 3, 2005, pp. 194-205.

[41] A. M. Schmidt, "Thermoresponsive Magnetic Colloids," Colloid and Polymer Science, Vol. 285, No. 9, 2007, pp. 953-966.

[42] A. Elaissari and V. Bourrel, "Thermosensitive Magnetic Latex Particles for Controlling Protein Adsorption and Desorption," Journal of Magnetism and Magnetic Materials, Vol. 225, No. 1-2, 2001, pp. 151-155.

[43] F. Sayer, G. Güven and E. Pişkin, "Magnetically Loaded Poly(methyl methacrylate-co-acrylic acid) Nano-particles," Colloid and Polymer Science, Vol. 284, No. 9, 2006, pp. 965-978.

[44] M. Lattuada and T. A. Hatton, "Functionalization of Monodisperse Magnetic Nanoparticles," Langmuir, Vol. 23, No. 4, 2007, pp. 2158-2168.

[45] J-J. Yuan, S. P. Armes, Y. Takabayashi, K. Prassides, C. A. P. Leite, F. Galembeck and A. L. Lewis, "Synthesis of Biocompatible Poly[2-(methacryloyloxy)ethyl phosphorylcholine]-Coated Magnetite Nanoparticles, Langmuir, Vol. 22, No. 26, 2006, pp. 10989-10993.

[46] R. A. Wassel, B. Grady, R. D. Kopke and K. J. Dormer, "Dispersion of Super Paramagnetic Iron Oxide Nanoparticles in Poly(d,l-lactide-co-glycolide) Microparticles," Colloids and Surfaces A: Physicochemical and Engineering Aspects, Vol. 292, No. 2-3, 2007, pp. 125-130.

[47] H. Mouaziz, S. Braconnot, F. Ginot and A. Elaïssari, "Elaboration of Hydrophilic Aminodextran Containing Submicron Magnetic Latex Particles," Colloid and Polymer Science, Vol. 287, No. 3, 2009, pp. 287-297.

[48] H. Mouaziz, R. Veyret, A. Theretz, F. Ginot and A. Elaïssari, "Aminodextran Containing Magnetite Nanoparticles for Molecular Biology Applications: Preparation and Evaluation," Journal of Biomedical Nanotechnology, Vol. 5, No. 2, 2009, pp. 172-181.
[49] F. Sauzedde, A. Elaïssari and C. Pichot, "Hydrophilic Magnetic Polymer Latexes. 1. Adsorption of Magnetic Iron Oxide Nanoparticles onto Various Cationic Latexes," Colloid and Polymer Science, Vol. 277, No. 9, 1999, pp. 846-855.

[50] E. Pollert, K. Knížek, M. Maryško, A. Lančok, J. Boháček, D. Horák and M. Babič, "Magnetic Poly(glycidyl methacrylate) Microspheres Containing Maghemite Prepared by Emulsion Polymerization," Journal of Magnetism and Magnetic Materials Vol. 306, No. 2, 2006, pp. 241-247.

[51] C. Yang, H. Liu, Y. Guan, J. Xing, J. Liu and G. Shan, "Preparation of Magnetic Poly(Methylmethacrylate-Divinylbenzene-Glycidylmethacrylate) Microspheres by Spraying Suspension Polymerization and their Use for Protein Adsorption," Journal of Magnetism and Magnetic Materials, Vol. 293, No. 1, 2005, pp. 187-192.

[52] D. Horak, M. Babic, H. Mackova and M. J. Benes, "Preparation and Properties of Magnetic Nano- and Microsized Particles for Biological and Environmental Separations," Journal of Separation Science, Vol. 30, No. 11, 2007, pp. 1751-1772.

[53] D. Horak, M. Babic, H. Mackova and M. J. Benes, "Preparation and Properties of Magnetic Nano- and Microsized Particles for Biological and Environmental Separations," Journal of Separation Science, Vol. 30, No. 11, 2007, pp. 1751-1772.

[54] C. C. Berry, S. Wells, S. Charles and A. S. G. Curtis, "Dextran and Albumin Derivatised Iron Oxide Nanoparticles: Influence on Fibroblasts in Vitro," Biomaterials, Vol. 24, No. 25, 2003, pp. 4551-4557.

[55] A. L. Autenshlyus, N. A. Brusenstov and A. Lockshim, "Magnetic-sensitive Dextran-Ferrite Immunosorbents (for Diagnostic and Therapy)," Journal of Magnetism and Magnetic Materials, Vol. 122, No. 1-3, 1993, pp. 360363.

[56] D. Charmot, "Preparation of Monodisperse, Magnetizable, Composite Metal/Polymer Microspheres," Progress in Colloid and Polymer Science, Vol. 79, 1989, pp. 94-100.

[57] L. P. Ramirez and K. Landfester, "Magnetic Polystyrene Nanoparticles with a High Magnetite Content Obtained by Miniemulsion Processes," Macromolecular Chemistry and Physics, Vol. 204, No. 1, 2003, pp. 22-31.

[58] S. Lu and J. Forcada, "Preparation and Characterization of Magnetic Polymeric Composite Particles by Miniemulsion Polymerization," Journal of Polymer Science Polymer Chemistry Edition, Vol. 44, No. 13, 2006, pp. 4187-4203.

[59] F. Caruso, A. S. Susha, M. Giersig and H. Mohwald, "Magnetic Core-shell Particles: Preparation of Magnetite Multilayers on Polymer Latex Microspheres," Advanced Materials, Vol. 11, No. 11, 1999, pp. 950-953.

[60] S.-Z. Hsiao, J.-L. Ou, Y. Sung, C.-P. Chang and M.-D. Ger, "Preparation of Sulfate- and Carboxyl-functionalized Magnetite/Polystyrene Spheres for Further Deposition of Gold Nanoparticles," Colloid and Polymer Science, Vol. 288, No. 7, 2010, pp. 787-794. 
[61] D. L. Pavia, G. M. Lampman, G. S. Kriz and J. A. Vyvyan, "Introduction to Spectroscopy," Harcourt Brace College Publishers, New York, 2008.

[62] J. L. Zhang, R. S. Srivastava and R. D. K. Misra, "Core-Shell Magnetite Nanoparticles Surface Encapsulated with Smart Stimuli-Responsive Polymer: Synthesis, Characterization, and LCST of Viable Drug-targeting Delivery System," Langmuir, Vol. 23, No. 11, 2007, pp. 6342-6351.

[63] M. Ma, Y. Zhang, W. Yu, H. Y. Shen, H. Q. Zhang and N.
$\mathrm{Gu}$, "Preparation and Characterization of Magnetite Nanoparticles Coated by Amino Silane," Colloids and Surfaces A: Physicochemical and Engineering Aspects, Vol. 212, No. 2-3, 2003, pp. 219-226.

[64] P. Govindaiah, Y. J. Jung, J. M. Lee, T-J. Park, D. Y. Ryu, J. H. Kim and I. W. Cheong, "Monodisperse and Fluorescent Poly(Styrene-co-Methacrylic Acid-co-2-Naphthyl Methacrylate) $/ \mathrm{Fe}_{3} \mathrm{O}_{4}$ Composite Particles," Journal of Colloid and Interface Science, Vol. 343, No. 2, 2010, pp. 484-490. 